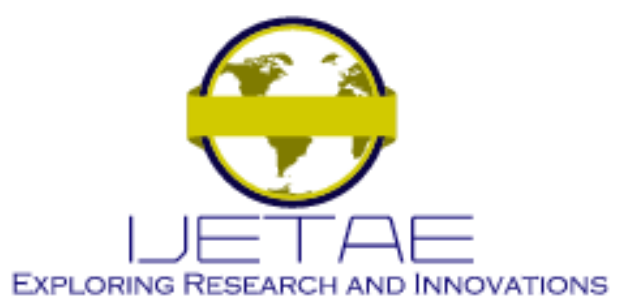

International Journal of Emerging Technology and Advanced Engineering

Website: www.ijetae.com (E-ISSN 2250-2459, Scopus Indexed, ISO 9001:2008 Certified Journal, Volume 11, Issue 11, November 2021)

Manuscript Received: 06 October 2021, Received in Revised form: 03 November 2021, Accepted: 10 November 2021 DOI: 10.46338/ijetae1121_14

\title{
Effects of Material Properties in Fabricating the Assistive Headrest Orthosis
}

\author{
Mohd Hazwan Mohamed Norli ${ }^{1}$, Madya Mastika Ahmad², Wan Nur Fatini W. Dagang ${ }^{3}$, Mohd Hafiz Mohd Noh, \\ Abdul Halim Abdullah ${ }^{* 5}$ \\ ${ }^{I}$ Department of Mechanical Engg., Politeknik Banting Selangor, Jalan Sultan Abdul Samad, 42700 Banting, Selangor Malaysia. \\ ${ }^{2}$ Department of Mechanical Engineering, Politeknik Kuching Sarawak, 93050 Kuching, Sarawak Malaysia \\ ${ }^{3,4, * 5}$ School of Mechanical Engg, College of Engineering, Universiti Teknologi MARA, 40450 Shah Alam, Selangor Malaysia. \\ (*Corresponding Author's Email: halim471@uitm.edu.my)
}

\begin{abstract}
These days, numerous decisions and efforts are contributing to cerebral palsy $(\mathrm{CP})$ cases. Patient with spastic or dyskinetic CP has to survive independently, where most of the time is spent in a wheelchair. An extension headrest must be applied to maximize independence and functionality in the sitting position for routine activities. This study aims to investigate the effects of material selection in fabricating the 3D-printed adjustable headrest. Expected headrest users would be children (age seven to nine years old). There are five materials in this research: Polycarbonate (PC), Polylactic Acid (PLA), Acrylonitrile Butadiene Styrene (ABS), Polyamide (Nylon), and Polyethylene Terephthalate (PETG). In the designing process, Computer-Aided Design (CAD) software focuses on designing the structure and Finite Element Analysis (FEA) software to analyze various parts. To conclude this study, PLA is chosen as the best material based on the best stress, deformation, and safety factors.
\end{abstract}

Keywords-- Adjustable headrest; finite element analysis; material selection; 3D printing

\section{INTRODUCTION}

Cerebral palsy refers to a group of conditions with variable severity that experienced certain developmental features in the standard [1]. It affects the motor function of children and has more psychological difficulties than normal children [2]. Cerebral palsy is incurable, but the rapidly growing advancement in medical management has assisted the patients in living a better quality of life and, in some cases, independently.

Children with cerebral palsy can have several problems such as muscle weakness, stiffness, slowness, shakiness, and difficulty balancing. The severity of the issues can be ranged from mild to severe conditions [3]. Zulkapli et al., 2016 [4], good sitting positions are required for CP children to stabilize their head and trunk together with alignment.
A reasonable postural control condition is needed to achieve a stabilized resting. However, the situation was also associated with functional neuromuscular alterations, contributing to the lack of head control in resting position [5]. Thus, a suitable headrest with improved functions such as attach ability, economically inclined, and user friendly is essential to improve their sitting position and posture.

The development of an adjustable headrest was proposed in this project to fulfill the CP children's needs. This paper focuses on predicting the best material selection to fabricate the adjustable headrest using 3D printing technology. In this study, five types of 3D printing materials are proposed for the fabrication process using a 3D printer. The materials are ABS (Acrylonitrile Butadiene Styrene), Nylon (Polyamide), PETG (Polyethylene Terephthalate), PC (Polycarbonate), and PLA (Polylactic Acid). Polylactic Acid (PLA) is one of the common materials used for the 3D printing process. PLA can be considered a renewable resource and biodegradable plastic because it is manufactured from corn starch as a raw material. PLA is an affordable and versatile plastic that makes it helpful in making large-sized prototypes, pattern making, and many more. ABS (Acrylonitrile Butadiene Styrene) is a thermoplastic polymer. It is a strong, durable, heat-resistant, and somewhat flexible plastic with remarkable impact mechanical properties. Therefore, ABS can be used for mechanical purposes and electrical purposes. Nylon is a synthetic linear thermoplastic polyamide with excellent mechanical characteristics that make it exceptionally durable, strong, and versatile. It serves many purposes, from clothing to industry. Another type of 3D printing material in the thermoplastic family is PETG (Polyethylene Terephthalate), which combines PET and glycol. PETG has both the combination of simplicity of PLA 3D printing and the strength of ABS. 


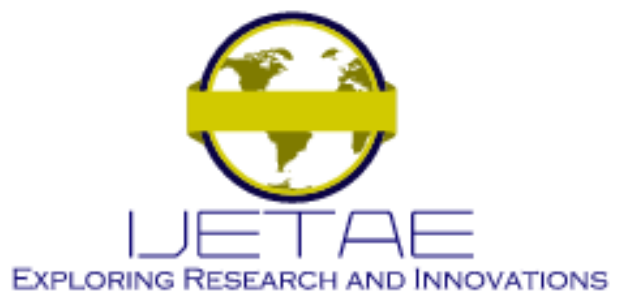

International Journal of Emerging Technology and Advanced Engineering

Website: www.ijetae.com (E-ISSN 2250-2459, Scopus Indexed, ISO 9001:2008 Certified Journal, Volume 11, Issue 11, November 2021)

Hardness, impact and chemical resistance, elasticity, and transparency and among the characteristic of PETG. Polycarbonate (PC) filament is very different from the other four filaments. It is lightweight but solid [6-9]. Although it is transparent, it has high impact resistance and tensile strength.

The current product available in the market was in universal sizes, heavy and rigid [6,7]. Thus, the objective of this project was to propose a customized product that managed to be designed for patient-specific, lightweight, good strength, and safe products using 3D printing technology.

\section{MATERIAL \& METHODS}

The headrest factored adjustability heavily into its design to better facilitate individuals who are using it. A press-fit assembly is chosen for its uncomplicated mechanism as well as ball locking bolts. The headrest should be capable of accommodating all shapes and sizes. A clamp mechanism [6] is used to secure the headrest to any wheelchair in use. A buckle strap to tighten the headrest to the user's head is optional.

\section{A. Material Properties}

There are five 3D printing materials considered, specifically ABS (Acrylonitrile Butadiene Styrene), Nylon (Polyamide), PETG (Polyethylene Terephthalate), PC (Polycarbonate), and PLA (Polylactic Acid). A set of predetermined loading conditions is applied to the headrest, given by $1.8 \mathrm{kPa}$ [7], $5 \mathrm{kPa}, 10 \mathrm{kPa}, 15 \mathrm{kPa}, 20 \mathrm{kPa}$, and 25 $\mathrm{kPa}$, respectively. Mechanical properties have been compiled [8] and summarised in Table 1. All materials are subjected to a loading condition of $1.8 \mathrm{kPa}$ as most materials failed at $5 \mathrm{kPa}$, rendering any analysis for other pressures null.

TABLE 1.

Mechanical Properties of Selected Materials

\begin{tabular}{llll}
\hline \hline Material & $\begin{array}{l}\text { Young } \\
\text { Modulus } \\
(\mathrm{MPa})\end{array}$ & $\begin{array}{l}\text { Poisson } \\
\text { ratio }\end{array}$ & $\begin{array}{l}\text { Yield } \\
\text { strength } \\
(\mathrm{MPa})\end{array}$ \\
\hline ABS & 2.3 & 0.36 & 35.9 \\
Nylon & 2.0 & 0.35 & 39.0 \\
PC & 2.2 & 0.43 & 53.0 \\
PETG & 3.3 & 0.39 & 27.8 \\
PLA & 2.6 & 0.36 & 62.1 \\
\hline \hline
\end{tabular}

\section{B. Loading \& Boundary Conditions}

A set of predetermined loading conditions is applied to the headrest. Distributed pressure at the headrest is assigned at $1.8 \mathrm{kPa}$ [7], representing the expected load during the headrest. Increment of pressure magnitudes of 5 $\mathrm{kPa}, 10 \mathrm{kPa}, 15 \mathrm{kPa}, 20 \mathrm{kPa}$, and $25 \mathrm{kPa}$ are also considered to predict the product's safety at a higher impact load. Figure 1 illustrates the pressure loading at the headrest and fixed constraint at the distal end.

\section{C. $3 D$ Printing}

The headrest was fabricated using a $3 \mathrm{D}$ printer. The finalized design CAD files were converted to an STL (Standard Triangle Language) file format before calibrating the process parameter in a slicer software, in this instance, Ultimaker Cura 4.3. Processing parameters such as extruding temperature, bed temperature, and infill speed were calibrated to achieve a uniform layer height of 0.24 $\mathrm{mm}$. The infill density used is reduced to $10 \%$, as an infill density between $10 \%$ and $20 \%$ will suffice for basic 3D prototypes [9]. It is corroborated by Redwood et al., 2017 [10], for a prototype where the form is essential, it can be printed with very low infill $(10 \%)$, saving significantly on cost and time. To conclude the process, fabrication is completed using the Ender Creality CR-10S5 3D printer. The parameter for the Ender Creality CR-10S5 3D printer is shown in Table 2.

TABLE 2:

Ender Creality CR-10S5 Parameter

\begin{tabular}{cc}
\hline \hline Machine type & CR-10S5 \\
Print size & $500 \times 500 \times 500 \mathrm{~mm}$ \\
Package weight & $22.8 \mathrm{Kg}$ \\
Nozzle diameter & $0.4 \mathrm{~mm}$ \\
Control system & Win, xp, mac, vista, Linux \\
Software & Cura, Simplify3D, Repetier- \\
host \\
File format & Obj, Stl, G-code \\
Print speed & $60 \mathrm{~mm} / \mathrm{s}-100 \mathrm{~mm} / \mathrm{s}$ \\
Filament diameter & $1.75 \mathrm{~mm}$ \\
Support filament & PLA/ABS/TPU/wood/carbon \\
& fiber/Copper \\
Power requirement & Input:110V-220V, Output \\
\end{tabular}




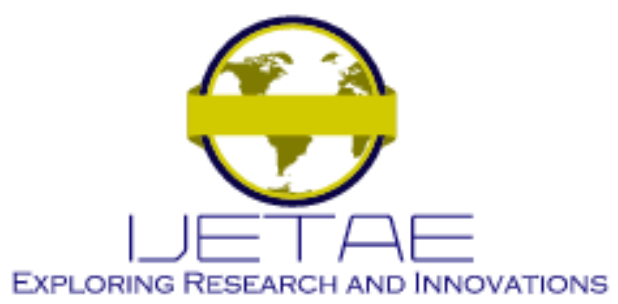

International Journal of Emerging Technology and Advanced Engineering

Website: www.ijetae.com (E-ISSN 2250-2459, Scopus Indexed, ISO 9001:2008 Certified Journal, Volume 11, Issue 11, November 2021)

\section{RESULTS \& DISCUSSION}

\section{A. Effects of Material Selections}

Five 3D printing materials, namely ABS, Nylon, PETG, PC, and PLA, have been subjected to a load of $1.8 \mathrm{kPa}$ [7]. Table 2 shows the stress and deformation distribution in ABS, Nylon, PC, PETG, and PLA. It can be established that PETG with 25.45 MPa has the lowest stress compared to other materials utilized and most likely the least to yield under pressure. The material that will most likely be the fastest to yield under pressure is ABS with $28.80 \mathrm{MPa}$. It is in line with Jones, 2009 [11], indicating that a significant Von Mises stress implies the material is closer to the yield point, thus exacerbating fracture. A low value denotes material is least likely to fracture due to the material being closer to the yield point.

Subsequent FEA analysis yields the stress distribution in the headrest, as shown in Figure 1. The color contour scale shows blue as the minimum stress and red as the maximum stress, a range of values from 0 to $26.80 \mathrm{MPa}$. The affected area is the adjustable mechanism of the headrest, where the more prevalent red color represents the maximum stress in PETG.
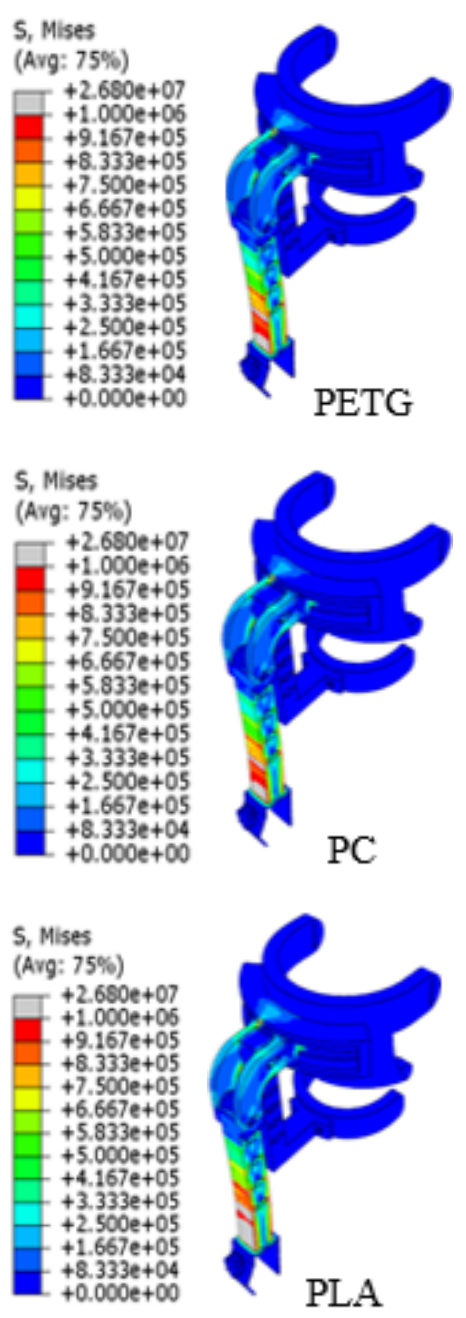

Figure 1: Stress distribution in the headrest

The more prevalent blue color denotes the material has a distribution of minimum Von Mises stress, thus do not yield under the loading pressure applied. While the red area shows the maximum stress endured, the material has not undergone failure. The color grey represents failure or yield. Theoretically, failure happens when the Von Mises stress exceeds the value of yield strength of any given material. The portion of the color scale is adjusted to distribute evenly across the stress range, the value being lower than 26.80 MPa. The adjustment added shows that at the specific grey color contour, the height adjustment part of the headrest will yield under pressure. 


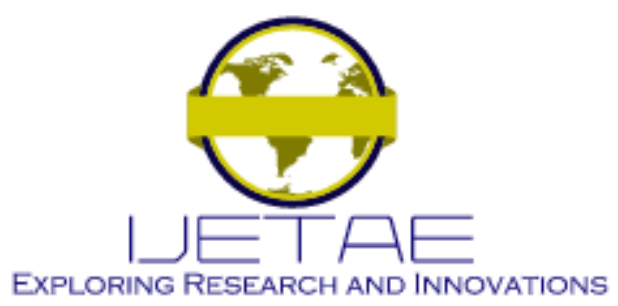

International Journal of Emerging Technology and Advanced Engineering

Website: www.ijetae.com (E-ISSN 2250-2459, Scopus Indexed, ISO 9001:2008 Certified Journal, Volume 11, Issue 11, November 2021)

Within the confines of deformation, it is established that ABS will be most likely to yield under pressure with a displacement of $0.9964 \mathrm{~mm}$ as opposed to nylon with $0.6017 \mathrm{~mm}$. ABS is known for its strength and printability [12]. The high deformation substantiates the fact. The FEA analysis in Figure 2 indicates the deformation the materials can withstand when subjected to pressure. The principle of color contour affected to Von Mises stress is applicable here. The deformation can easily be distinguished in where it can be seen the exact place failure will occur because of the more prevalent red color contour.
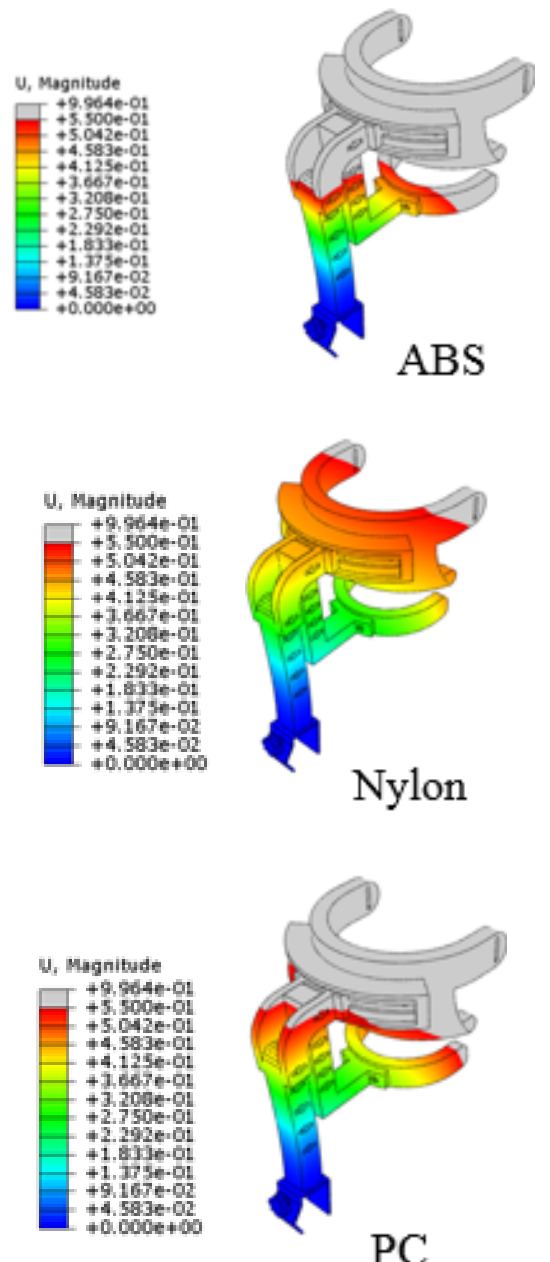
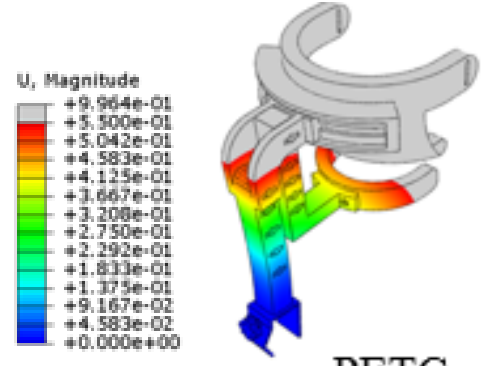

PETG
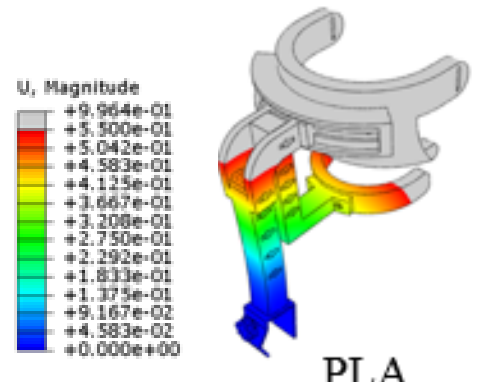

PLA

Figure 2: Deformation in the headrest

An incremental loading pressure is applied to predict the product's safety at a higher impact load, specifically to 1.8 $\mathrm{kPa}, 5 \mathrm{kPa}, 10 \mathrm{kPa}, 15 \mathrm{kPa}, 20 \mathrm{kPa}$, and $25 \mathrm{kPa}$, respectively. The resulting analysis is presented in Figure 3 and Figure 4, where both the Von Mises stress and deformation are directly proportional to the pressure applied. It can be observed that by cross-referencing Figure 3 with Table 2, as a result of comparing the yield strength of the selected materials with Von Mises stress obtained Greene et al., 2016 [13], all materials except PLA will fracture at $5 \mathrm{kPa}$. The lower stress obtained is concurrent with Gibson et al., 2009 [14], where parts made using these materials on FDM machines may display lower strength areas than the initial value because of interfacial regions in the layers and possible voids in the elements. 


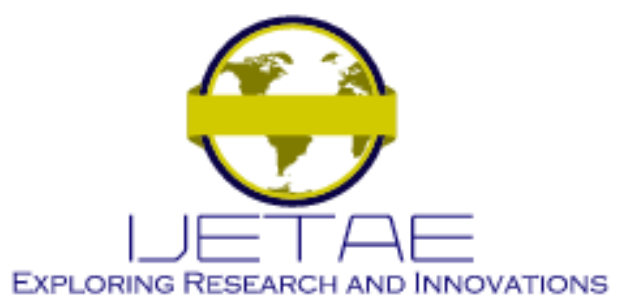

International Journal of Emerging Technology and Advanced Engineering

Website: www.ijetae.com (E-ISSN 2250-2459, Scopus Indexed, ISO 9001:2008 Certified Journal, Volume 11, Issue 11, November 2021)

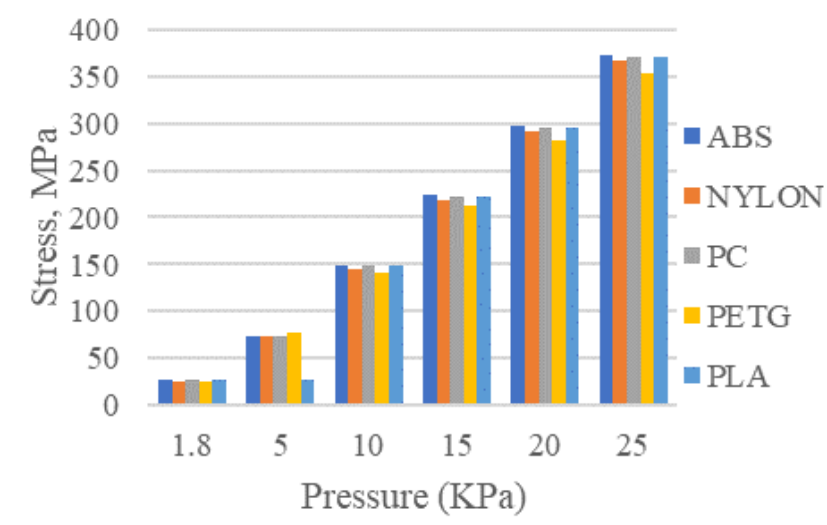

Figure 3: Stress distribution by different loading conditions

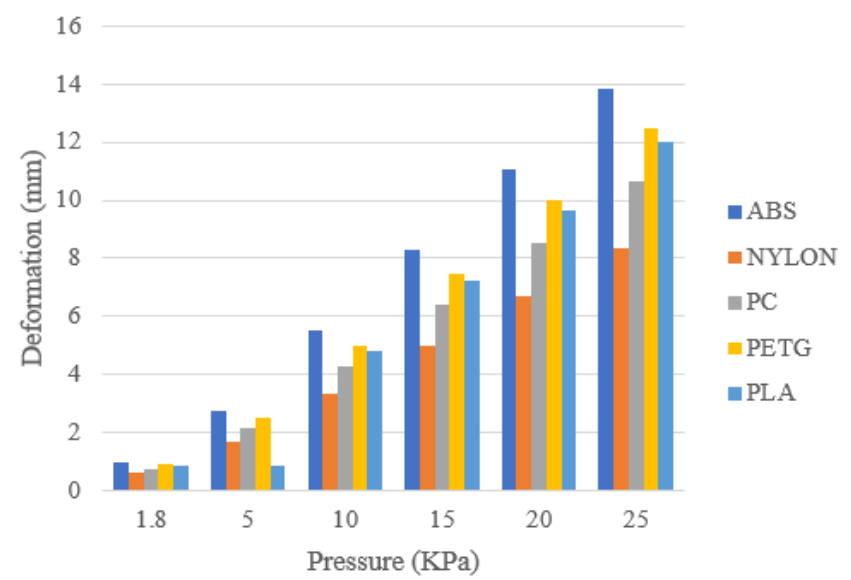

Figure 4: Deformation displacement by different loading magnitude

The most straightforward and widely used approach in addressing variability and uncertainty in engineering design is the factor of safety (FoS), or sometimes a unanimous term safety factor [15]. The use of safety factors to assure that a structure can perform its intended function constrains failure risk to an acceptable level [16]. The findings are summarized in Table 3 and Figure 5. The PLA and PC materials are recognized for a safety factor of 2.33 and 1.99, respectively, suggesting both as suitable materials for the headrest. Ultimately ABS, nylon, and PETG would be considered objectionable materials as the ratio did not fall into the acceptable safety factor for this design relative to all materials. They are too close to the value of 1.00. It can be observed PETG has the lowest safety factor ratio with 1.09 , followed by ABS with a ratio of 1.34 , and nylon with a ratio of 1.49 .
Any value less than 1.00 signifies that the material does not comply with the safety factor. For that matter, said material is considered to fail and unsafe to be used for the intended application. It is supported by Sarma et al., 2020 [17], where three materials were compared for their safety factor using the same boundary conditions and fixed constraints.

TABLE 3

: Factor of Safety for Selected Materials

\begin{tabular}{llll}
\hline \hline Material & $\begin{array}{l}\text { Yield } \\
\text { strength } \\
(\mathrm{MPa})\end{array}$ & $\begin{array}{l}\text { Max. von } \\
\text { Mises Stress } \\
(\mathrm{MPa})\end{array}$ & FoS \\
\hline ABS & 35.9 & 26.80 & 1.34 \\
Nylon & 39.0 & 26.18 & 1.49 \\
PC & 53.0 & 26.66 & 1.99 \\
PETG & 27.8 & 25.45 & 1.09 \\
PLA & 62.1 & 26.66 & 2.33 \\
\hline \hline
\end{tabular}

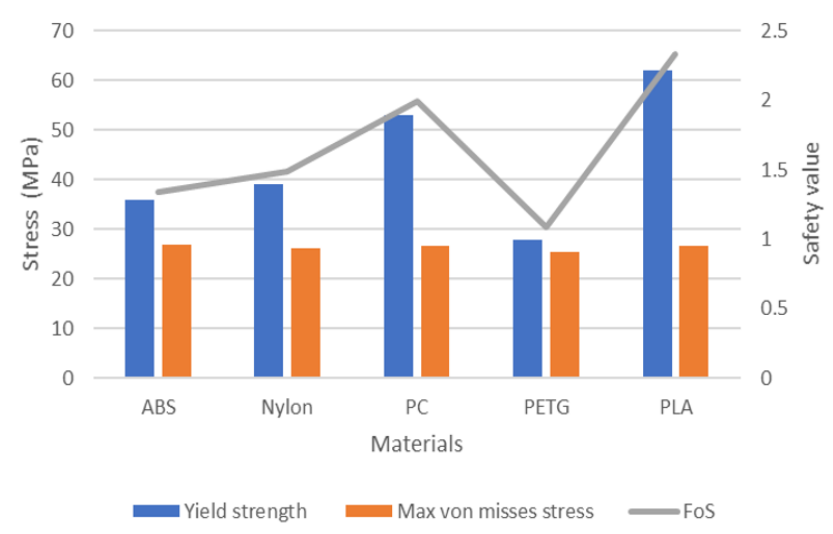

Figure 5: Comparison of yield strength, maximum stress, and safety factor for five different materials

\section{B. 3D Printed of Headrest Orthosis}

Apart from the findings in finite element analysis, parameter setting in 3D printing activity is also to be considered. The results suggested PLA as the most appropriate material selection as summarised in the factor of safety criteria. Table 4 indicates the projected parameter in fabricating the headrest at different infill settings for PLA material. 


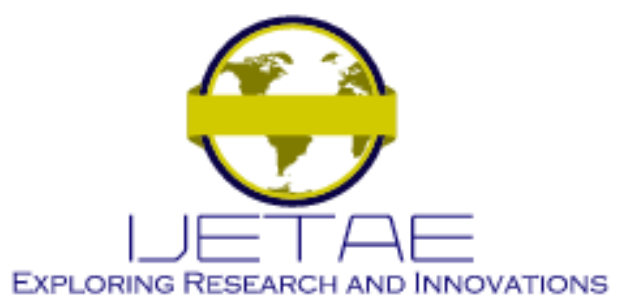

International Journal of Emerging Technology and Advanced Engineering

Website: www.ijetae.com (E-ISSN 2250-2459, Scopus Indexed, ISO 9001:2008 Certified Journal, Volume 11, Issue 11, November 2021)

Figure 6 shows the fabricated headrest product using 3D printing technology at different views. The model is designed and ready with the capability to be customized based on the patient. An additional parameter can be set to meet the customer requirement at preferable weight, time to fabricate, including color and material selection.

TABLE 4:

Projected Parameters Based on Infill Density

\begin{tabular}{ccc}
\hline \hline Infill & Weight $(\mathrm{g})$ & Time \\
\hline $20 \%$ & 1041 & $3 \mathrm{~d} 1 \mathrm{~h} 21 \mathrm{~m}$ \\
$40 \%$ & 1273 & $3 \mathrm{~d} 10 \mathrm{~h} 47 \mathrm{~m}$ \\
$60 \%$ & 1505 & $3 \mathrm{~d} 20 \mathrm{~h} 22 \mathrm{~m}$ \\
$80 \%$ & 1738 & $4 \mathrm{~d} 5 \mathrm{~h} 22 \mathrm{~m}$ \\
$100 \%$ & 1941 & $5 \mathrm{~d} 17 \mathrm{~h} 44 \mathrm{~m}$ \\
\hline \hline
\end{tabular}

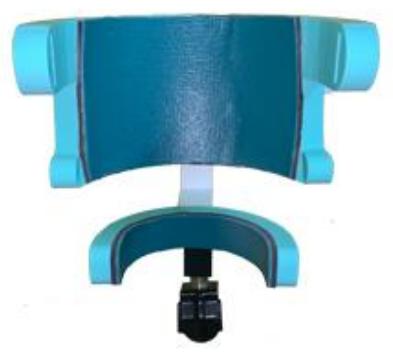

(a) Front View

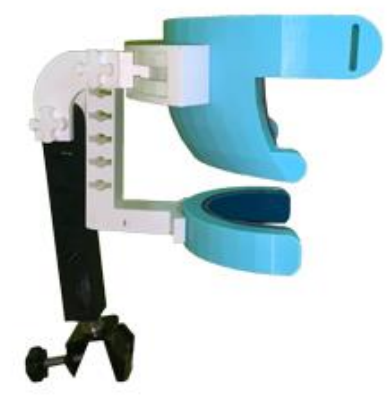

(b) Right View

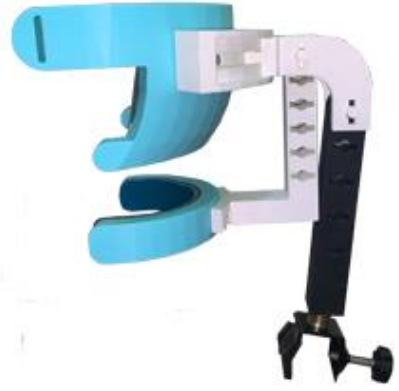

(c) Left View

Figure 6: 3D printed model of headrest at different views

\section{CONCLUSION}

The improvement of adjustable headrest for total body involvement in $\mathrm{CP}$ children has been successfully analyzed and fabricated. Consequently, the effects of material properties in ABS, Nylon, PC, PETG, and PLA have been determined and evaluated. In terms of Von Mises stress, PETG has the lowest stress at 25.45 MPa. It made for an excellent material for high-impact mechanical parts. Subsequently, concerning deformation, ABS with the highest deformation of $0.9964 \mathrm{~mm}$ is the least likely to yield under pressure, owing to its strength. About the safety factor, conversely, PLA has the highest ratio in safety factor with 2.33 , connoting it a highly reliable material. As a result, the PETG, ABS, and PLA are considered for fabrication from the five materials tested. Considering several factors such as mechanical properties, cost, printing time, durability, and evaluating data compiled, PLA is the most optimum choice to print the headrest. The model also was successfully fabricated using 3D printing technology employing the FDM process. Later research that can be conducted is the effect of infill density as other beneficial factors.

\section{Acknowledgment}

This research was supported by Jabatan Pendidikan Politeknik \& Kolej Komuniti (JPPKK) under Grant Ref. No. KPT.JPP.PPPP.700-1 Jld.31(91). We thank and acknowledge the Ministry of Higher Education, Malaysia, and our colleagues from the Politeknik Banting Selangor also UiTM Shah Alam, who provided advice and expertise in the research work. 


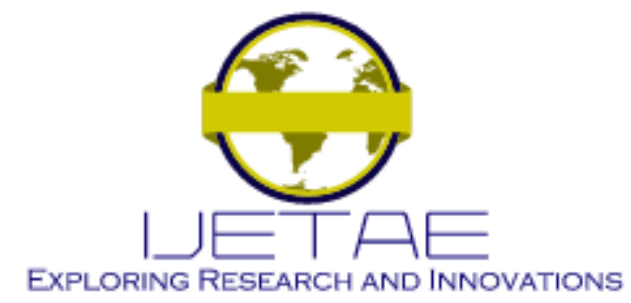

\section{International Journal of Emerging Technology and Advanced Engineering}

\section{Website: www.ijetae.com (E-ISSN 2250-2459, Scopus Indexed, ISO 9001:2008 Certified Journal, Volume 11, Issue 11, November 2021)}

\section{REFERENCES}

[1] Graham, H. Kerr, Rosenbaum, Peter, Paneth, Nigel, Dan, Bernard, Lin, Jean-Pierre, Damiano, Diane L. Lieber, Richard L. (2016). Cerebral palsy. Nature Reviews Disease Primers, 2(1), 15082. doi:10.1038/nrdp.2015.82

[2] Singer, H. S., Mink, J., Gilbert, D. L., \& Jankovic, J. (2015). Chapter 20 - Cerebral Palsy. In H. S. Singer, J. Mink, D. L. Gilbert, \& J. Jankovic (Eds.), Movement Disorders in Childhood (pp. 453-574): Elsevier Science.

[3] Carne, R., Kennedy, R., Lanigan, A., Ong, K., Randall, M., D., Reddihough, \& Touzel, B. (2006). Cerebral Palsy: An Information Guide for Parents: Royal Children's Hospital, Melbourne.

[4] Zulkapli, Nur, Saat, Nur, \& Kamaralzaman, Sazlina. (2016). Postural Control Influence on Upper Extremity Function among Children with Cerebral Palsy: A Literature Review. Jurnal Sains Kesihatan Malaysia, 14. doi:10.17576/jskm-2016-1402-02.

[5] Martinez-Mihi, V., Silvestre, F. J., Orellana, L. M., \& SilvestreRangil, J. (2014). Resting position of the head and malocclusion in a group of patients with cerebral palsy. J Clin Exp Dent, 6(1), e1-6. doi: $10.4317 /$ jced.51129

[6] Heston, Tim. (2016). Reimagining the C-clamp. The Fabricator, 4, 5-8.

[7] Franz, M., Durt, A., Zenk, R., \& Desmet, P. M. A. (2012). Comfort effects of a new car headrest with neck support. Applied Ergonomics, 33(2), 336-343. doi:https://doi.org/10.1016/j.apergo.2011.06.009

[8] Callister, W. D., \& Rethwisch, D. G. (2014). Materials Science and Engineering: Wiley.

[9] Bhatia, S. K., \& Ramadurai, K. W. (2017). 3-Dimensional Printing of Medical Devices and Supplies 3D Printing and Bio-Based Materials in Global Health: An Interventional Approach to the Global Burden of Surgical Disease in Low-and Middle-Income Countries: Springer International Publishing.

[10] Redwood, B., Schöffer, F., \& Garret, B. (2017). The 3D Printing Handbook: Technologies, Design and Applications: 3D Hubs B.V.

[11] Jones, R. M. (2009). Deformation Theory of Plasticity: Bull Ridge Pub.

[12] Greene, S., Lipson, D., Mercado, A., \& Soe, A. H. (2016). Design And Manufacture Of A Scalable Prosthetic Hand Through The Utilization Of Additive Manufacturing Worcester Polytechnic Institute.

[13] Gibson, I., Rosen, D. W., \& Stucker, B. (2009). Additive Manufacturing Technologies: Rapid Prototyping to Direct Digital Manufacturing: Springer US.

[14] Chang, Kuang-Hua. (2013). Chapter 2 - Structural Analysis. In Kuang-Hua Chang (Ed.), Product Performance Evaluation with CAD/CAE (pp. 43-119). Boston: Academic Press.

[15] Moreland, Dean W. (2009). Mechanical Systems Safety. In G.E.M.P. D, A. Larsen, \& T. Sgobba (Eds.), Safety Design for Space Systems: Elsevier Science.

[16] Sarma, Tribedi, Kumar Saxena, Kuldeep, Majhi, Vinayak, Pandey, Divya, Prakash Tewari, Ravi, \& Sahai, Nitin. (2020). Development of active ankle foot orthotic device. Materials Today: Proceedings. doi:https://doi.org/10.1016/j.matpr.2020.01.143
[17] Alafaghani, Ala'aldin, Qattawi, Ala, Alrawi, Buraaq, \& Guzman, Arturo. (2017). Experimental Optimisation of Fused Deposition Modelling Processing Parameters: A Design-for-Manufacturing Approach. Procedia Manufacturing, 10, 791-803. doi:https://doi.org/10.1016/j.promfg.2017.07.079

[18] Aslanzadeh, Samira, Saghlatoon, Hossein, Honari, Mohammad Mahdi, Mirzavand, Rashid, Montemagno, Carlo, \& Mousavi, Pedram. (2018). Investigation on electrical and mechanical properties of $3 \mathrm{D}$ printed nylon 6 for $\mathrm{RF} /$ microwave electronics applications. Additive Manufacturing, 21, 69-75. doi:https://doi.org/10.1016/j.addma.2018.02.016

[19] Mehraein, Hootan. (2018). Impact of process parameters on mechanical properties of 3D printed polycaprolactone (PCL) parts.

[20] Torres, Jonathan, Cotelo, Jose, Karl, Justin, \& Gordon, Ali. (2015). Mechanical Property Optimization of FDM PLA in Shear with Multiple Objectives. JOM, 67. doi:10.1007/s11837-015-1367-y

[21] Campbell, Leah, Lau, Adriel, Pousett, Brittany, Janzen, Ernie, \& Raschke, Silvia. (2018). How Infill Percentage Affects the Ultimate Strength of 3D-Printed Transtibial Sockets During Initial Contact. Canadian Prosthetics \& Orthotics Journal doi:10.33137/cpoj.v1i2.30843

[22] Roesler, J., Harders, H., \& Baeker, M. (2007). Mechanical Behaviour of Engineering Materials: Metals, Ceramics, Polymers, and Composites: Springer Berlin Heidelberg.

[23] Ćwikła, Grzegorz, Grabowik, Cezary, Kalinowski, Krzysztof, Paprocka, Iwona, \& Ociepka, Piotr. (2017). The influence of printing parameters on selected mechanical properties of FDM/FFF 3Dprinted parts. IOP Conference Series: Materials Science and Engineering, 227, 012033. doi:10.1088/1757-899X/227/1/012033

[24] Moradi, Mahmoud, Meiabadi, Saleh, \& Kaplan, Alexander. (2019). 3D Printed Parts with Honeycomb Internal Pattern by Fused Deposition Modelling; Experimental Characterisation and Production Optimisation. Metals and Materials International, 25(5), 1312-1325. doi:10.1007/s12540-019-00272-9

[25] Young, Devin, Otten, Cara, \& Czabaj, Michael. (2019). Effect of Processing Parameters on Interlayer Fracture Toughness of Fused Filament Fabrication Thermoplastic Materials: Proceedings of the 2018 Annual Conference on Experimental and Applied Mechanics (pp. 77-79).

[26] Fernandez-vicente, Miguel, Calle, Wilson, Ferrándiz, S., \& Conejero, Andres. (2016). Effect of Infill Parameters on Tensile Mechanical Behavior in Desktop 3D Printing. 3D Printing and Additive Manufacturing, 3, 183-192. doi:10.1089/3dp.2015.0036

[27] Dan, Bobby Tang, Khodos, Daniel Robert, Khairallah, Oliver, Ramlal, Richi, \& Budhoo, Yougashwar. (2018). The Effect of the 3D Printing Process on the Mechanical Properties of Materials.

[28] Chaudhari, Madhuri, Jogi, Bhagwan, \& Pawade, R. S. (2018). Comparative Study of Part Characteristics Built Using Additive Manufacturing (FDM). Procedia Manufacturing, 20, 73-78. doi:10.1016/j.promfg.2018.02.010

[29] Hamzah, S. R. (2018). Adjustable Headrest for Total Body Involvement in Cerebral Palsy Children. Universiti Teknologi MARA.

[30] Wan Fadzil, W. F. A., Mazlan, M. A., Hanapiah, F. A., \& Abdullah, A. H. (2019). Effects of Infill Density on 3D Printed Socket for Transtibial Prosthetic Leg. Paper presented at the 5th International Exchange and Innovation Conference on Engineering \& Sciences, Japan. 